\title{
ABORTO NO BRASIL: VISÕES IDEOLÓGICAS
}

\section{ARTIGO ORIGINAL}

RIBEIRO, João Batista Almeida ${ }^{1}$

RIBEIRO, João Batista Almeida. Aborto no Brasil: Visões ideológicas. Revista Científica Multidisciplinar Núcleo do Conhecimento. Ano 06, Ed. 01, Vol. 01, pp. 8491. Janeiro de 2021. ISSN: 2448-0959, Link de acesso: https://www.nucleodoconhecimento.com.br/lei/visoes-ideologicas

\section{RESUMO}

O aborto durante o decorrer de muitas décadas foi visto como um ato imoral, tendo sido passível de grande repúdio pelas antigas civilizações, as legislações estadistas e o negativismo das doutrinas religiosas sempre se mostraram um grande embaraço a essa prática. A criminalização do aborto se arguiu em épocas remotas, tempos em que a igreja majorava grande influência sob impérios e nações, por consequência, as ordens religiosas usavam de tal status para satisfazer interesses das próprias congregações. Mas mesmo com situações adversas, a cultura dessa técnica permaneceu agindo em todo o mundo, só no Brasil estima-se que mais de 503 mil abortos são realizados por ano, denotasse que clandestinamente o aborto ainda persiste em existir. O fundamentalismo religioso do maior país católico do mundo, seguido pelo conservadorismo estatal, é um grande embaraço à aceitação de tal prática. A pesquisa foi construída com base nestas problemáticas: Qual a relação entre $\mathrm{o}$ aborto e as ideologias existentes no Brasil? Existe miscigenação entre o ordenamento jurídico e o fundamentalismo religioso? O presente artigo tem como objetivo fazer uma análise acerca dos magistérios da igreja e as legislações atuais, abordando as modalidades abortivas, demonstrando a veemência dessas práticas

\footnotetext{
${ }^{1}$ Discente de Direito - Universidade José do Rosário Vellano - Discente de Tecnologia em Segurança No Trabalho - Unicesumar.
} 
que atravessaram décadas, e que ainda hoje permanecem constantes em todas as classes sociais no Brasil.

Palavras-Chave: Aborto, Direitos Humanos, Legislação Civil, teologia.

\section{INTRODUÇÃO}

Através de jornais e dos diversos meios de comunicação, a população mundial vivencia constantemente a luta incessante pelo direito à vida, de acordo com dados da ONU (Organização das Nações Unidas) dezesseis mil crianças morrem todos os dias de fome, uma a cada cinco segundos, ainda nesse contexto de miserabilidade um bilhão de adultos são totalmente analfabetos, nessa luta por sobrevivência a maioria padece à mercê da fome e da guerra. Nesse contexto de sofrimento as discussões em prol da vida são amplamente instigadas pelos programas governamentais, visando diminuir os impactos dessa condição humana de miserabilidade. Enquanto milhares de crianças morrem de fome e lutam pela vida, meio que direta ou indiretamente pela ação do homem, outras nem chegam a nascer, pois são negadas no próprio seio materno. Essa pesquisa tem como objetivo analisar a questão do aborto no Brasil, abordando o seu enfrentamento ideológico dentro das legislações vigentes e os magistérios de doutrinas cristãs.

\section{MATERIAIS E MÉTODOS}

A metodologia adotada para a elaboração deste trabalho consiste em reunir, pesquisar, e analisar as várias informações publicadas sobre o tema, Compreende, portanto, numa busca por pesquisa bibliográfica, em fonte primária, selecionando-se e sintetizando-se as ideias que se relacionam com o tema para melhor compreendêlo, destacando-se as citações literais de trabalhos científicos, legislações e doutrinas religiosas. 


\section{ABORTO: IMPETUOSO E ATUAL}

De acordo com o código civil de 2002 a personalidade civil da pessoa começa quando essa nasce com vida; mas a mesma legislação em vigor defende que desde a concepção, o nascituro tem seus direitos respeitados.

Assim, o legislador ao editar o texto do Código Civil do Brasil de 2002 (BRASIL, 2002, p.01), dispôs no art. 2 in verbis: "Art. 2 A personalidade civil da pessoa começa do nascimento com vida; mas a lei põe a salvo, desde a concepção, os direitos do nascituro."

Muitos se perguntam quem é o nascituro; mas a origem da palavra vem do latim nasciturus, "aquele que há de nascer", se algo vem a nascer preceitua-se a existência de vida. Durante muitas décadas esse direito à vida vem sendo questionado, a batalha entre laboratórios, farmacêuticos e entidades religiosas se tornou em todo o mundo uma briga constante; de um lado mercados que arrecadam milhões de dólares com técnicas e medicamentos abortivos, de outro vemos a herança de milênios de anos, religiões que tentam manter a integridade de seus magistérios, defendendo o direito à vida e repudiando métodos que a contradizem.

De acordo com o catecismo da igreja católica (CIC §2270)

A vida humana deve ser respeitada e protegida de maneira absoluta a partir do momento da concepção. Desde o primeiro momento de sua existência, o ser humano deve ver reconhecido os seus direitos de pessoa, entre os quais o direito inviolável de todo ser inocente à vida.

Existem hoje diversos tipos de aborto, algumas técnicas incluem envenenamento salino, onde se injeta no feto uma solução salina, isso lhe causa a morte em até 12 horas por desidratação, hemorragia entre outros fatores, a sucção onde através desta insere-se no útero um tubo que suga e absorve o feto, outro método é a dilatação ou curetagem, uma lamina cortante que espedaça o feto em pedaços facilitando a retirada, método por si muito tradicional, mas a Pílula RU-486 mais conhecida como a "pílula do dia seguinte" é a mais usada. 
Aníbal Bruno preleciona que (1976, p.159):

Segundo se admite geralmente, provocar aborto é interromper o processo fisiológico da gestação, com a consequente morte do feto. Tem-se admitido o aborto ou como expulsão prematura do feto, ou como a interrupção do processo de gestação. Mas nem um nem outro desses fatos bastará isoladamente para caracterizá-lo.

O mundo vivencia grandes mudanças, diferentes pautas têm se atentado para questões genealógicas e culturais, a Assembleia Mundial da Saúde (2020), incluiu recentemente um programa de "saúde sexual e reprodutiva", propondo a garantia para que os indivíduos tenham uma vida sexual prazerosa e segura, garantindo o acesso à informação e aos métodos contraceptivos. Diante de sinalizações em prol de tais técnicas, vemos que desde tempos remotos até os dias atuais, existe uma tendência na familiarização do aborto que ultrapassa décadas. A exemplo da antiguidade do tema os EUA (Estados Unidos da América) contam com um programa favorável ao aborto desde o século XX, porem a emenda Hayde aprovada em 1976, limita o acesso, sendo possível apenas em casos de estupro, incesto ou risco de vida da mãe; esse dispositivo controla o uso de recursos federais para a prática do aborto.

\section{DA ATUALIDADE AS DIVERGÊNCIAS}

O aborto é um tema que carrega ideologias políticas e partidárias, visa poderios influenciadores. Em 2015 de acordo com dados do SUS (Sistema Único de Saúde), somente o Brasil atendeu 200 mil mulheres após procedimentos de abortos mal sucedidos, muitas mulheres se submetem às formas obscuras em clínicas clandestinas. Dilma Rousseff em 2013, sancionou a lei 12.845, dispondo sobre o atendimento obrigatório e integral de pessoas em situação de violência sexual, dispensando apresentação de provas ou boletins de ocorrência, devendo o SUS obrigatoriamente dispor de meios que garantam a interrupção da gravidez em decorrência de estupro.

O legislador ao editar o texto da lei 12.845 de 2013 (BRASIL, 2013, p.01), dispôs no art. 10 in verbis: 
Art. $1^{\circ}$ Os hospitais devem oferecer às vítimas de violência sexual atendimento emergencial, integral e multidisciplinar, visando ao controle e ao tratamento dos agravos físicos e psíquicos decorrentes de violência sexual, e encaminhamento, se for o caso, aos serviços de assistência social.

No Brasil reputa-se criminoso o aborto, mas a legislação vigente no art.128 do Código Penal admite-o em duas hipóteses, quando necessário, caso não exista outro meio para salvar a vida da gestante ou se a gravidez resulta de estupro e o aborto tem o consentimento da gestante. Temos aqui um choque entre a legislação vigente o princípio do duplo efeito na igreja católica, pois se o aborto acontece indiretamente na tentativa de salvar a vida da mãe, de acordo com a própria igreja ele é lícito e justificado pelo princípio da causa com duplo efeito.

De acordo com o sacerdote Brendan Coleman, existem certas ações que produzem dois efeitos: um bom e o outro mau, sendo tolerável a acepção de tais atos (COLEMAN, 2018).

É lícito praticar tais atos desde que se preencham as seguintes condições: (i) $\mathrm{O}$ efeito bom seja diretamente intencionado; o efeito mau seja apenas tolerado. (ii) O efeito mau não seja anterior ao efeito bom, pois não se devem cometer males para daí tirar bem. O fim não justifica os meus maus. (iii) $\mathrm{O}$ efeito bom sobre purgue, por seus valores e sua densidade, o efeito mau. (iv) Não há outro recurso para obter o efeito bom. (PERGUNTE E RESPONDEREMOS, 2003).

O direito a vida é assegurado na carta magma do Brasil, sendo um dos grandes pilares de sua soberania, “... a atual Constituição, claramente, assegura o próprio direito à vida, reiterando, no bojo do artigo 5ํㅡㄴ, ser vedada a pena de morte no país. Assim, mesmo nos crimes mais hediondos, o criminoso não pode ser punido com a morte." (MARTINS FILHO, 2013). O aborto pode acontecer de duas formas: o espontâneo e o provocado, o espontâneo acontece por causas naturais, também chamados de indireto onde não existe a intervenção humana, o provocado passa por procedimentos e técnicas específicas sendo mais conhecidos por direto ou causado. A divergência entre a igreja e o aborto se encontra no fato que desde o momento da concepção, a vida humana já é imediatamente criada por Deus, não podendo ninguém humano, nem nenhuma autoridade apontar a disposição sobre essa vida. 


\section{ABORTO NA LEGISLAÇÃO BRASILEIRA E NA ÓTICA CRISTÃ}

O artigo 5 da CRF (CONSTITUIÇÃO FEDERAL, 1988) veda a pena de morte no país, o código Civil (2002) reitera desde a concepção, os direitos do nascituro, sendo possível inclusive a essa herdar antes mesmo de nascer, o bebê que irá nascer chamado legalmente de nascituro, ainda no ventre terá direito à herança. A lei garante a ele, desde a concepção, seus direitos sucessórios, porém a participação na herança, fica condicionada ao nascimento com vida, assim, se o bebê não nascer, a partilha será feita entre os herdeiros vivos, ressalvada a parte da genitora. Para o código Penal (1940) o aborto é considerado um crime contra a vida humana. Mas é inegável que milhares de mulheres arriscam e perdem suas vidas em busca dessa prática. A igreja católica desde tempos antigos, refuta a imoralidade dessa prática, o catecismo evidência (CIC §2271):

O Catecismo da Igreja Católica sempre zelou pela vida humana, e com isso esclarece que, "Desde o século I, a Igreja afirmou a maldade moral de todo aborto provocado". Este ensinamento não mudou. Continua invariável. O aborto direto, quer dizer, querido como um fim ou como um meio, é gravemente contrário à lei moral.

Nos mesmos viés o código de Direito Canônico preceitua (Can, 871): "Os fetos abortivos, se estiverem vivos, serão batizados, enquanto possível."

Por sua vez Ronald Dworkin (2010) ressalta que:

Qualquer criatura humana, inclusive o embrião mais imaturo, é um triunfo da criação divina ou evolutiva que produz, como se fosse do nada, um ser complexo e racional, e igualmente um triunfo daquilo que comumente chamamos de "milagre" da reprodução humana, que faz com que cada novo ser humano seja, ao mesmo tempo, diferente dos seres humanos que o criaram e uma continuação deles.

O aborto se consuma com a morte "causada" do feto, não sendo preciso necessariamente haver a expulsão para a configuração do crime, pode-se também ocorrer na modalidade de tentativa, nesta a manobra abortiva falha, o feto em consequência sobrevive com sequelas; esse ato configura circunstâncias judiciais desfavoráveis (Art. 59 do $\mathrm{CP}$ ), sendo usadas contra a genitora em caso de 
condenação. Agora, se esse feto mesmo com o uso de táticas abortivas sobrevive e vem a "nascer "com vida, e posteriormente praticam novas condutas visando a morte, teremos aqui configurado os crimes de tentativa de aborto e homicídio, ou infanticídio dependendo o fato. O terceiro que atua na provocação do aborto, sendo medico ou qualquer pessoa, fazendo esse, com o consentimento da gestante, respondera pelo crime tipificado no artigo 26 do código penal (1940), podendo sofrer reclusão de até quatro anos; porem se esse terceiro atua por vontade própria, sem consentimento da genitora, a título de exemplo: o médico que realiza procedimento abortivo a pedido da família, ou ainda deixa de prescrever remédio vital a saúde da gestação, responde esse pelo crime tipificado no artigo 125 do código penal, (1940) com pena de até dez anos de reclusão. Porém essa constante criminalização do aborto tem criado ambientes degradantes para as pessoas que o veem como única saída, nas palavras do ministro Barroso (2016).

Conforme o Habeas Corpus/RJ 124.306 no Supremo Tribunal Federal (BARROSO, 2016, p. 16):

De um lado, já se demonstrou amplamente que a tipificação penal do aborto produz um grau elevado de restrição a direitos fundamentais das mulheres. Em verdade, a criminalização confere uma proteção deficiente aos direitos sexuais e reprodutivos, à autonomia, à integridade psíquica e física, e à saúde da mulher, com reflexos sobre a igualdade de gênero e impacto desproporcional sobre as mulheres mais pobres. Além disso, criminalizar a mulher que deseja abortar gera custos sociais e para o sistema de saúde, que decorrem da necessidade de a mulher se submeter a procedimentos inseguros, com aumento da morbidade e da letalidade.

Porém se de um lado a esfera legal tem um aporte de tentar garantir direitos fundamentais, noutra diversas organizações de cunho religioso se fecham a tal flexibilização. O documento do Papa Paulo VI, Gaudium et Spes, na parte sobre o respeito da pessoa humana dispõe (GS 27):

Tudo quanto se opõe à vida, como seja toda a espécie de homicídio, genocídio, aborto, eutanásia e suicídio voluntário vão contra a dignidade da pessoa humana e ofendem gravemente a Deus, que é o autor da vida, confiou aos homens o encargo de preservá-la, com isso, "o aborto e o infanticídio são crimes abomináveis. 
O aborto é um tema complexo que tem causado muitas discussões em todo o mundo, desde tempos remotos diversas entidades tentam inibir tal prática, outras já o veem como um cunho necessário. A discriminação é tão grande que pouco se fala nesse tema, o problema maior é que milhares de mulheres perdem suas vidas; na busca por uma saída acabam se entregando a procedimentos mortais em clínicas clandestinas.

\section{CONSIDERAÇÕES FINAIS}

Destarte ressaltar assim, que o ordenamento jurídico repudia tal ato com veemência, mas que a luz dos direitos fundamentais tem se arguido discussões a fim de proteger e garantir a liberdade de expressão de cada ser humano. $O$ direito à vida é um bem indisponível, não podendo ninguém dispor ou apontar ações que a prejudiquem. Os documentos, doutrinadores e legislações citadas ressaltam a massificação com que o tema é tratado desde tempos antigos, mas alerta também acerca das consequências que tais ações podem causar em uma nação.

A vida é um bem comum, sendo um direito universal. A própria natureza clama por socorro, diante das ameaças do aquecimento global podemos ver que as mudanças climáticas são um alerta para a sobrevivência na terra. Os animais lutam pelos seus, defendem até a morte as suas crias, muitos são os casos de espécies que adotam outras, mas o ser humano em questão evoluiu para colocar em pauta a disposição da vida. $O$ aborto é um tema que constantemente causa conflitos e coloca em risco toda uma sociedade, infelizmente causa a morte de milhares de mulheres; a negligência ao tema tem sido algo estarrecedor. Vemos organizações que tentam salvar a vida desses fetos, apostando numa psicologia reversa com essas mães, porém o que pouco se encontra são sistemas de saúde que diminuam a dor de quem apostou por tal prática. Os constantes conflitos ideológicos têm levantado novas visões, essas que partem de premissas ligadas à preservação dos direitos fundamentais; fato é que essas discussões devem arguir novos rumos, talvez menos ou até mais conflitivos. 


\section{REFERÊNCIAS}

BRASIL. Constituição da República Federativa do Brasil de 1988. Brasília, DF: Presidência da República, [2016]. Disponível em: http://www.planalto.gov.br/ccivil_03/Constituicao/Constituiçao.

BRASIL. Lei no 10.406, de 10 de janeiro de 2002. Institui o Código Civil. Diário Oficial da União: seção 1, Brasília, DF, ano 139, n.

CONSTITUIÇÃO PASTORAL GAUDIUM ET SPES. Documentos do Concílio Ecumênico Vaticano II. São Paulo: Decreto-Lei 2.848, de 07 de dezembro de 1940. Código Penal. Diário Oficial da União, Rio de Janeiro, 31 dez. 1940.

MARTINS FILHO, Ives Gandra Da Silva. O Fenômeno da Terceirização e Suas Implicações Jurídicas*. Direito Público, [S.I.], v. 8, n. 43, jul. 2013. ISSN 2236-1766. Disponível em: $<$ https://www.portaldeperiodicos.idp.edu.br/direitopublico/article/view/2054>. Acesso em: 13 dez. 2020.

ONU. Aborto. disponível em: https://nacoesunidas.org/oms-proibicao-nao-reduznumero-de-abortos-e-aumenta-procedimentos-inseguros/ acesso em 19/11/2017

UOL NOTÍCIAS. Decisão (sobre aborto) é para adotar políticas públicas', diz Barroso. Conteúdo Estadão. Em Brasília 01/12/2016 às 08h47. Disponível em: $<$ https://noticias.uol.com.br/saude/ultimas-noticias/estado/2016/12/01/decisao-sobreaborto-e-para-adotar-politicas-publicas-diz-barroso.htm> acesso em: 20 out. 2018

Enviado: Dezembro, 2020.

Aprovado: Janeiro, 2021. 